\title{
TEXTURE FORMED BY PLATELET ALIGNMENT IN CERAMIC PLATELET CERAMIC MATRIX COMPOSITES
}

\author{
W-Y. LI AND O. T. SØRENSEN \\ Materials Department, Ris $\varnothing$ National Laboratory, DK-4000, Roskilde, Denmark
}

(Received 12· August 1994)

\begin{abstract}
$3 \mathrm{~mol} \%$ yttria stabilized zirconia matrix has been incorporated with $10 \mathrm{wt} \%$ single crystal $\alpha$-alumina platelets to enhance the mechanical reliability. The composites have been produced by different forming techniques, namely, slip casting, tape casting, and injection moulding followed by pressureless sintering. Relative density $\sim 99 \%$ has been obtained. Alignment of the platelets in the material was analyzed by processing the images taken from scanning electron microscopy. Strong texture was formed by the alignment of platelet. Mechanical properties of the composites were evaluated, and co-related to the alignment of the platelets.
\end{abstract}

KEY WORDS: Platelet, composite, texture, mechanical properties.

\section{INTRODUCTION}

Advanced technical ceramics have a number of very useful engineering properties, such as: high temperature strength, high hardness and stiffness, low density, low thermal expansion and thermal conductivity, good corrosion and oxidation resistance, good wear and erosion resistance. However ceramic materials generally suffer from an inherent brittleness and therefore give a low fracture toughness, which limits their applications to conditions where the ceramic components are only subjected to relatively low stresses. There is therefore a strong incentive towards developing tougher and thus more reliable ceramic materials which undergoes "graceful" rather than catastrophic failure.

A significant amount of research has been performed on ceramic matrix ceramic composites (CMCs) over the last 10-15 years in an attempt to improve the fracture toughness. Studies have shown that in comparison with monolithic ceramic materials, the CMCs which are ceramics containing ceramic reinforcements - particles, whiskers, platelets or fibres, offer many possibilities of toughening for instance by crack deflection/ crack branching, crack bridging and pull-out of the reinforcing phase.

It is well known that 3 mol\% yttria stabilized tetragonal zirconia (TZ3Y) has good room-temperature strength and fracture toughness due to the tetragonal-to-monoclinic $(t \rightarrow m)$ phase transformation triggered by mechanical stresses, creating a compressive stress field around the crack tip. This mechanism, however, does not operate at temperatures higher than the transformation temperature $\left(\sim 700-800^{\circ} \mathrm{C}\right)$, resulting in a significant strength degradation at a high temperature. Varying degrees of success 
have been achieved by reinforcing zirconia with alumina particles (Tsukuma et al., 1985a, 1985b; Sato et al., 1987, 1988; Kihara et al., 1988), whiskers (Roberts et al., 1991), and platelets (Heussner and Claussen, 1989; Huang and Nicholson, 1993). The toughening effect is considered to increase with the increase of the aspect ratio of the reinforcement. Mechanical property measurements of hot-pressed TZ3Y reinforced with silicon carbide whiskers have demonstrated a distinct increase in fracture toughness (Claussen et al., 1986; Akimune et al., 1988). However, whisker reinforced materials are not considered to be so attractive because of the toxicity of whiskers, and the high cost of processing such composites.

Attention in the last a few years has been, therefore, focused on platelet reinforcement as an alternative to whisker reinforcement in ceramic matrix composites, although the toughening effect is generally inferior to whiskers. The main advantages of using platelets compared with whiskers are the improved environmental safety, production economics, and thermal stability.

For materials containing grains or reinforcements with shape anisotropy, such as plate-, or needle-like morphology, generally develop textures during processing. Texture is commonly referred to as the preferred orientation of crystallographic axes of crystallites with respect to a fixed frame of reference in a polycrystalline specimen (Kahn and Bragg, 1968). Textures in ceramic materials are often introduced purposely to take advantage of anisotropic crystal properties (Jin et al., 1989; Kumakura et al., 1991), or to optimize the processing and overall properties (Watanabe et al., 1989, 1991; Wu et al., 1991). Methods used to produce textures can be green state forming techniques, for instance tape casting, extrusion, injection moulding, or slip casting.

Alumina platelet $\left(\mathrm{Al}_{2} \mathrm{O}_{3 \mathrm{pl}}\right)$ was chosen as reinforcement in TZ3Y composites in this project because of the commercial availability. Previously the platelet orientation in such composites produced by pressure filtration has been qualitatively studied and corelated to the various processing parameters and procedures (slurry viscosity, solids content, platelet content, loading rate, etc.) (Warner and Sørensen, 1991; Warner et al., 1992). In this paper, results obtained from recent work on $\mathrm{Al}_{2} \mathrm{O}_{3 \mathrm{pl}}-\mathrm{TZ3Y}$ composites produced by different forming techniques (slip casting, injection moulding, tape casting) are reported and discussed.

\section{METHODS AND MATERIALS}

Single crystal $\alpha-\mathrm{Al}_{2} \mathrm{O}_{3}$ platelet powder (Elf Atochem S.A. France, Grade T'0), and $3 \mathrm{~mol} \% \quad \mathrm{Y}_{2} \mathrm{O}_{3}$ stabilized $\mathrm{ZrO}_{2}$ (Tosoh TZ3YS) were used as the starting materials. The platelets' surfaces are hexagonal with an average size of $\sim 5 \mu \mathrm{m}$, and a thickness of $\sim 1 \mu \mathrm{m}$. The specific surface area of the platelet powder was measured to be $0.7 \mathrm{~m}^{2} \mathrm{~g}^{-1}$ using multi-point gas adsorption BET method (Micromeritics Gemini 2360). The matrix TZ3YS powder had a specific surface area of $\sim 6 \mathrm{~m}^{2} \mathrm{~g}^{-1}$, and the mean particle size was $\sim 0.3 \mu \mathrm{m}$.

It had been found that the as received platelet powder contained some large agglomerates which was detrimental for the sintering of the composites. The platelet powder was therefore processed to remove the agglomerates before being mixed with the matrix powder. The as received $\mathrm{Al}_{2} \mathrm{O}_{3}$ platelets were dispersed in ethanol using ultrasonic vibration for 6 minutes by an ultrasonic probe (Ultrasonic homogenizer 4710 series, Cole-Parmer Instrument Co. Chicago, USA), and followed by sieving through a $30 \mu \mathrm{m}$ sieve. The platelets-ethanol suspension was filtered using filter paper (Struers), and dried at $60^{\circ} \mathrm{C}$ for 48 hours. 
Composites containing $10 \mathrm{wt} \% \mathrm{Al}_{2} \mathrm{O}_{3 \mathrm{pl}}$ were produced by three different forming techniques, namely, slip casting, injection moulding, and tape casting.

Slip casting was carried out using standard plaster mould $(13 \times 5 \times 45 \mathrm{~mm})$. The slip was water - based, containing $36 \mathrm{vol} \%$ of solids, $0.5 \mathrm{wt} \%$ (per gram of dry powder) surfactant A6114, and $0.25 \mathrm{wt} \%$ (per gram of dry powder) PVP. The cast bars were dried and sintered at $1600^{\circ} \mathrm{C}$ for 2 hours.

Injection moulding used polystyrene binder in the formula, with $\sim 56$ vol\% solid loading, which is typically used for this process. The rectangular bars were formed by side inlet. Standard de-bindering conditions were used before the materials were sintered at the same nominal sintering parameters as those for slip cast samples.

Tape casting slip formula used for the composite was based on that for casting TZ3Y with a substitution of $\sim 11 \mathrm{wt} \% \mathrm{Al}_{2} \mathrm{O}_{3 \mathrm{pl}}$. The total solid loading was $\sim 23 \mathrm{vol} \%$. Casting was undertaken using the normal doctor blade. Green tapes $(21 \times 174 \mathrm{~cm})$ have been cut to smaller sizes using a normal guillotine (for paper-cutting). Up to 6 layers were laminated by hand rolling with ethanol applied between the layers.

De-bindering of the laminated samples was carried out at $600^{\circ} \mathrm{C}$ for $2 \mathrm{~h}$ with a heating, and a cooling rate of $6^{\circ} \mathrm{C} / \mathrm{h}$, which was followed by sintering. The nominal sintering parameters were identical to those used for materials produced by other techniques, except that the samples in this case were placed underneath an alumina plate to avoid warping.

Environmental Scanning Electron Microscope (ESEM), or normal Scanning Electron Microscope (SEM, Jeol JSM-840) were used to examine the microstructure and the platelet alignment on polished sections of the materials formed from different techniques. Quantitative analysis of the platelet alignment was performed by image processing technique.

Mechanical properties TZ3Y - $10 \mathrm{wt} \% \mathrm{Al}_{2} \mathrm{O}_{3 \mathrm{pl}}$ composites in terms of flexural strength and fracture toughness $\left(\mathrm{K}_{\mathrm{IC}}\right)$ have been characterized. At least 4 samples were tested for each measurement. The flexal strength was measured by four-point bending test. Tensile surface of the sample was sometimes polished for comparison. $\mathrm{K}_{\mathrm{IC}}$ values were obtained by both chevron notched beam (CNB), and indentation methods. It should be stressed that the absolute $\mathrm{K}_{\mathrm{IC}}$ values obtained by CNB may not be precise due to the fact that stable crack growth could not be obtained during the measurement. The data, however, are considered to be able to show the trend of the toughness for each material group.

Samples produced by slip casting were cut evenly into three bars along the longitudinal direction for the mechanical property measurement. Load was applied both parallel and normal to the cut surface.

\section{RESULTS AND DISCUSSION}

\section{PLATELET Orientation}

SEM observations showed that all the three forming methods produced some degree of platelet alignment. In slip cast sample bars, platelets were strongly aligned parallel to the two biggest walls of the mould. This was confirmed by the result from quantitative image analysis. Figure 1 shows some typical SEM taken from different areas of a slip cast bar.

Platelet orientation measurement obtained from the image analysis is presented in Figure 2. In this figure, the angle between the longitudinal direction of the sample and 


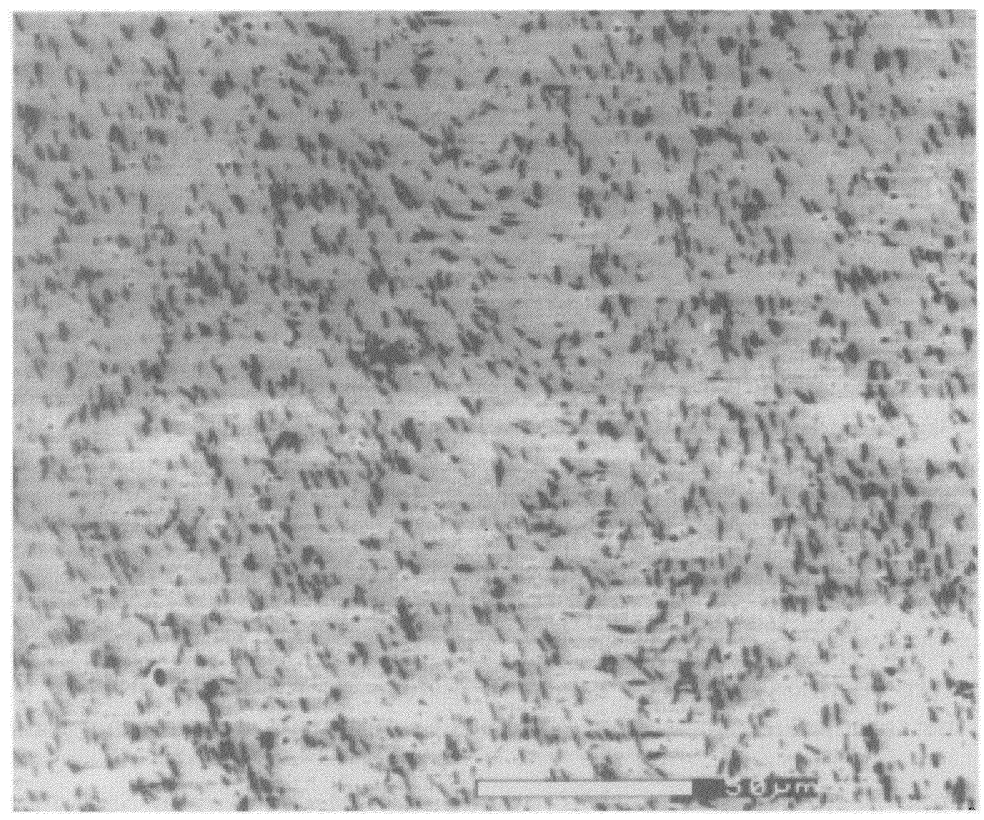

(a)

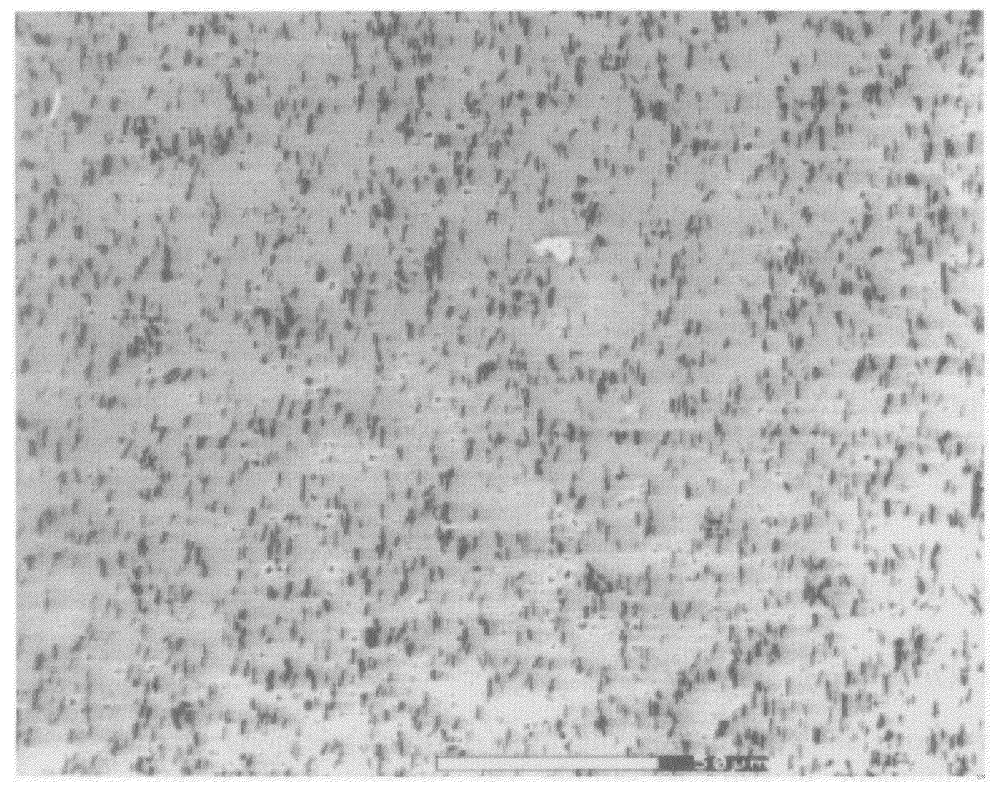

(b)

Figure 1 Typical SEM taken from different areas of a slip cast sample showing platelet alignment $\begin{array}{ll}\text { (a) near the centre } & \text { (b) near a wall of the mould }\end{array}$ 


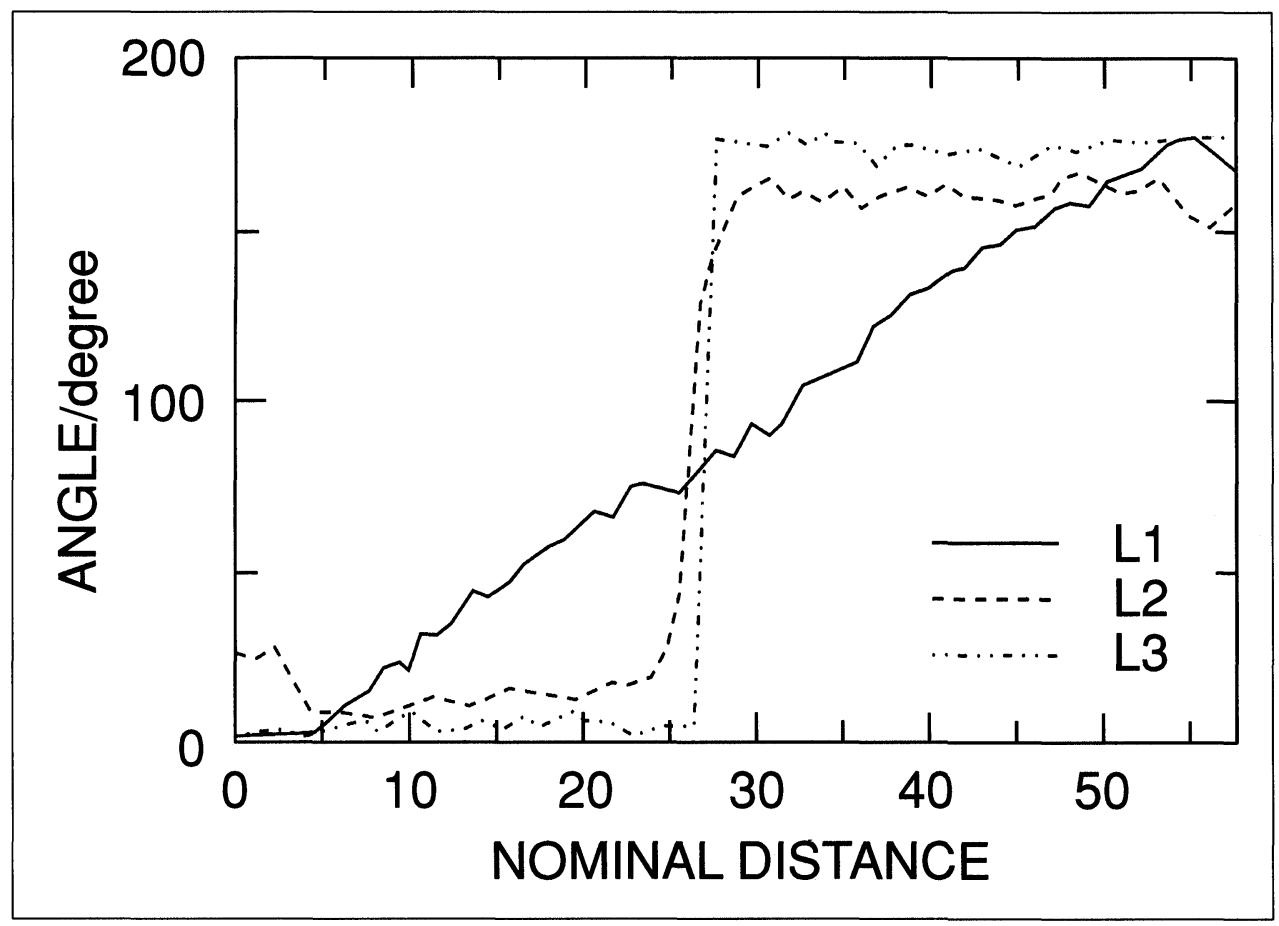

Figure 2 Platelet orientation as a function of position in a slip cast sample.

one surface of a platelet is shown as a function of nominal distance across the width of the sample. The three different curves in Figure 2 designated as L1, L2, and L3, represent results from three different levels from bottom to top along the longitudinal axis in the slip cast bar. 200-500 views were analyzed covering the sample surface. It is seen from Figure 2 that the orientation of the platelets in the sample near the bottom of the bar changes slowly from 0 to $180^{\circ}(\mathrm{L} 1)$, suggesting the presence of a considerably large platelet-orientation transition zone in this part of the sample. The orientations of the platelets in the other 2 levels change sharply for 0 to $180^{\circ}$ (L2), and $\sim 10$ to $165^{\circ}$ (L3), indicating that the transition zones here are small, which means that the platelets are well aligned all through the width of the sample. Results in Figure 2 are thus consistent to the visual observations as shown in Figure 1. The orientation of the platelets is schematically illustrated in Figure 3.

The feature of the platelet alignment in the slip cast sample may be affected by several factors, for example sample geometry, solid content in the slip, the permeability of the mould material, etc., as those shown for the whisker composites (Sandlin and Bowmen, 1992). In the present case strong texture was formed in a considerably large volume of the material so that it was possible to obtain a piece of sample with a roughly defined platelet orientation.

SEM of injection moulded and tape cast samples showed relatively weaker textures. SEM on large areas in the injection moulded bars revealed that only platelets close to the surfaces were lying parallel to the surfaces of the sample. Platelets in the main body of the sample were approximately randomly oriented. This is thought to be related 


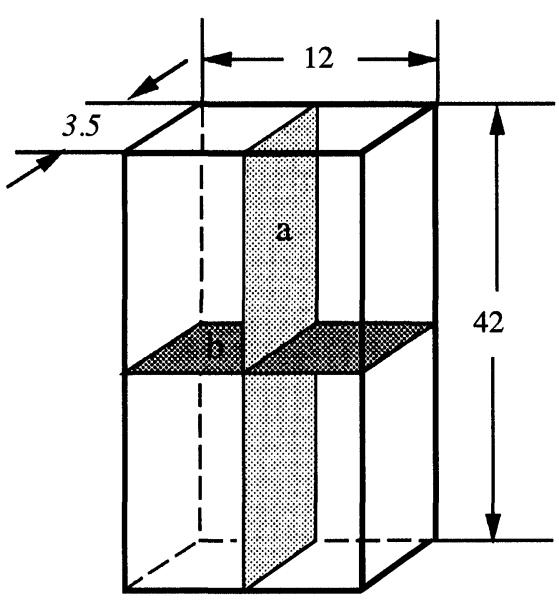

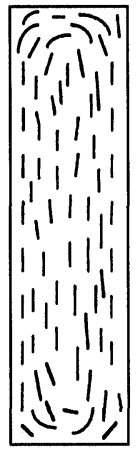

(a)

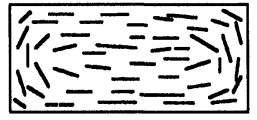

(b)

Figure 3 Schematic illustration of the platelet orientation in the slip cast sample.

to the way in which the compound was injected - side inlet, which is not the optimum method for obtaining aligned platelets.

For laminated tape cast samples, platelets were shown to have the tendency of lying parallel to the surfaces of the tapes. Tape casting has been reported to be an effective way to produce green sheets with aligned whiskers (Wu et al., 1991), or plate-like particles (Watanabe et al., 1989). The degree of alignment of the plate-like particles was found to be determined mainly by the powder content, and therefore the interaction between particles was a main cause for particle orientation (Watanabe et al., 1989). Thus higher degree of platelet alignment would be obtained by optimizing the tape cast slurry. The slurry used for tape casting in the present case might have been far from optimized. Further work is needed in order to produce better aligned platelet composite tapes.

\section{MECHANICAL Property Measurements}

Figure 4, shows the strength values for different material groups obtained from different forming techniques, or treated under different conditions. For injection moulded samples (group 1 and 2), it is seen that the strength values increased dramatically when the tensile surfaces are polished, reaching a maximum average value compared to other groups. This result indicates the smaller internal flaws formed due to the higher pressure used in this process $(\sim 30-40 \mathrm{MPa})$ in the injection moulded samples. The lower strength for un-polished injection moulded samples was due to the large surface flaws caused by the worn surfaces of the mould. Figure 5 shows a serials of fracture surface SEM on the injection moulded samples, which confirm that the fracture originated from the tensile surface when the sample was not polished (Figure 5a), and that defects under 


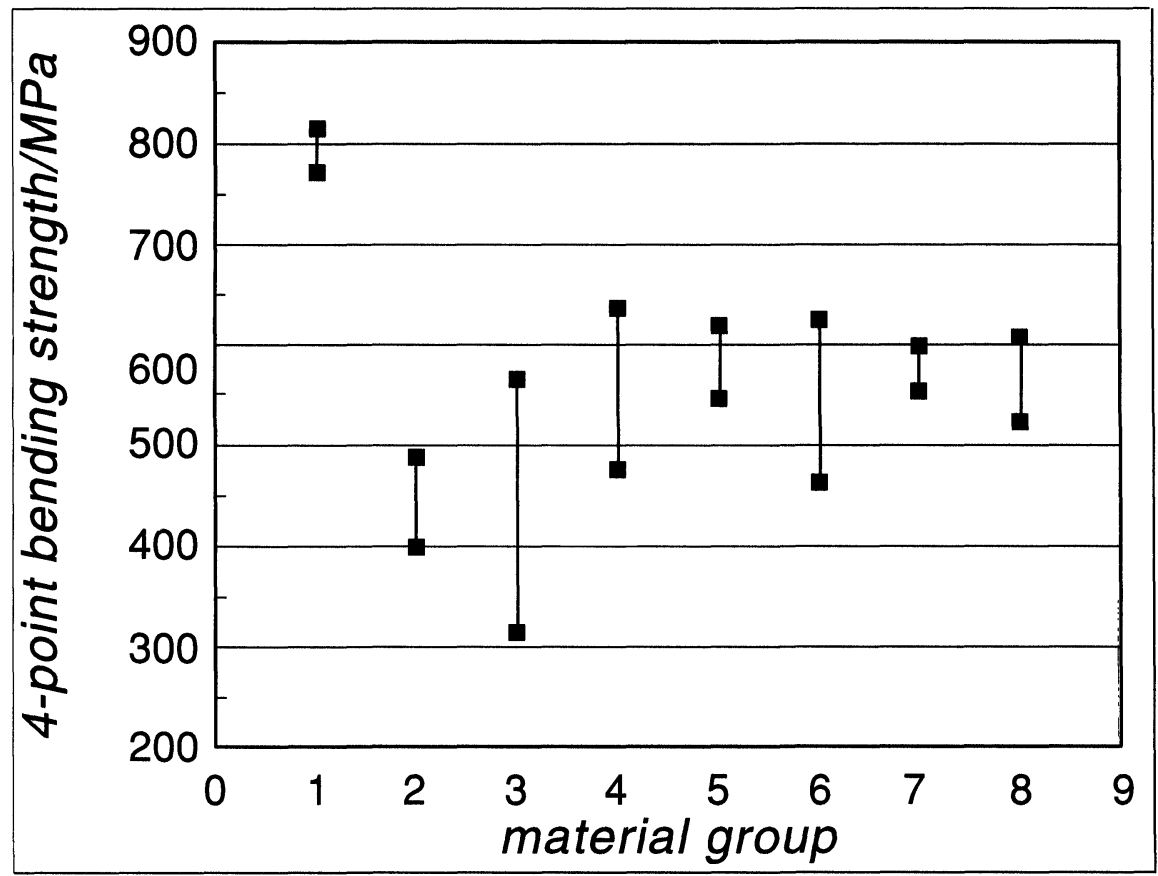

Figure 4 Strength values for different material groups. $1=$ injection moulded, polished: $2=$ injected moulded, not polished; 3 = tape east, laminated, not polished; $4=$ slip cast (middle), cracks propagate from an edge of a platelet, polished; $5=$ slip cast (middle), cracks propagate from a surface of a platelet, polished; 6 = slip cast (middle), cracks propagate from an edge of a platelet, not polished; 7 = slip cast (sides), cracks propagate from an edge of a platelet, polished; 8 = slip cast (sides), cracks propagate from a surface of a platelet, polished.

the surface, typically platelet agglomerates initiated the fracture when the tensile surface was polished (Figure $5 \mathrm{~b}, \mathrm{c}$ ).

The average strength value for the laminated tape cast material (Figure 4, group 3) is similar to the un-polished injection moulded samples. Large delamination flaws in the samples are believed to be responsible for the low strength in this case.

For slip cast samples, it is seen that the average strength values are not affected significantly by the surface conditions (Figure 4, compare group 4 with 6), the crack propagation direction relative to the orientation of platelets (Figure 4, compare group 4 with 5), and the texture formed by the platelet orientation (Figure 4, compare group $4,5$ with 7,8$)$. These results indicate that certain large flaws exist in the samples.

Figure 6 shows the $\mathrm{K}_{\mathrm{IC}}$ values measured by the two different methods: CNB and indentation (IND), for injection moulded and slip cast samples prepared in different ways. For the matrix material (TZ3Y) formed by slip casting (group 1), the two $\mathrm{K}_{\mathrm{IC}}$ values are the same. As $\mathrm{K}_{\mathrm{IC}}$ measured from IND and CNB reflects the crack resistance on a surface, and inside the body of the material, respectively, the results for the matrix thus suggest the similar crack resistance on the surface and inside the body. This is expected because there was no special texture in the material.

For injection mould composite samples (group 2), $\mathrm{K}_{\mathrm{IC}}$ from IND is $\sim 20 \%$ higher than that from CNB. This may be due to the texture formed on the surface, while the platelets were almost randomly oriented inside the material as mentioned earlier (platelet orientation section). 


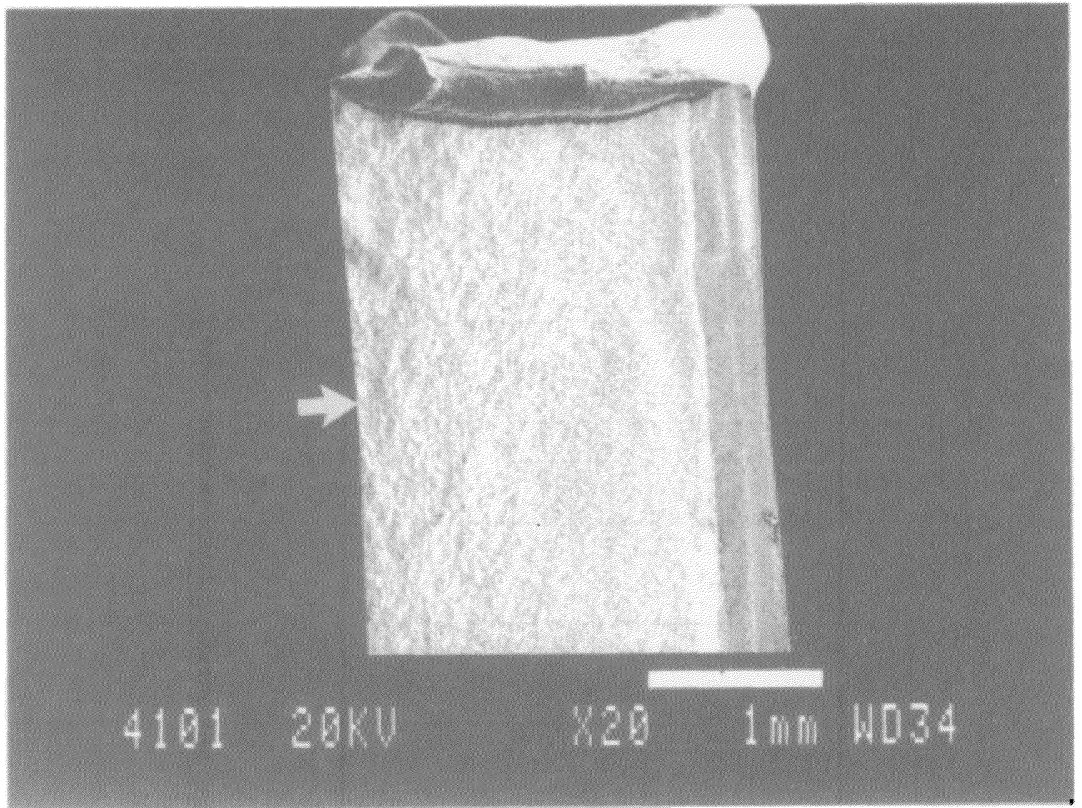

(a)

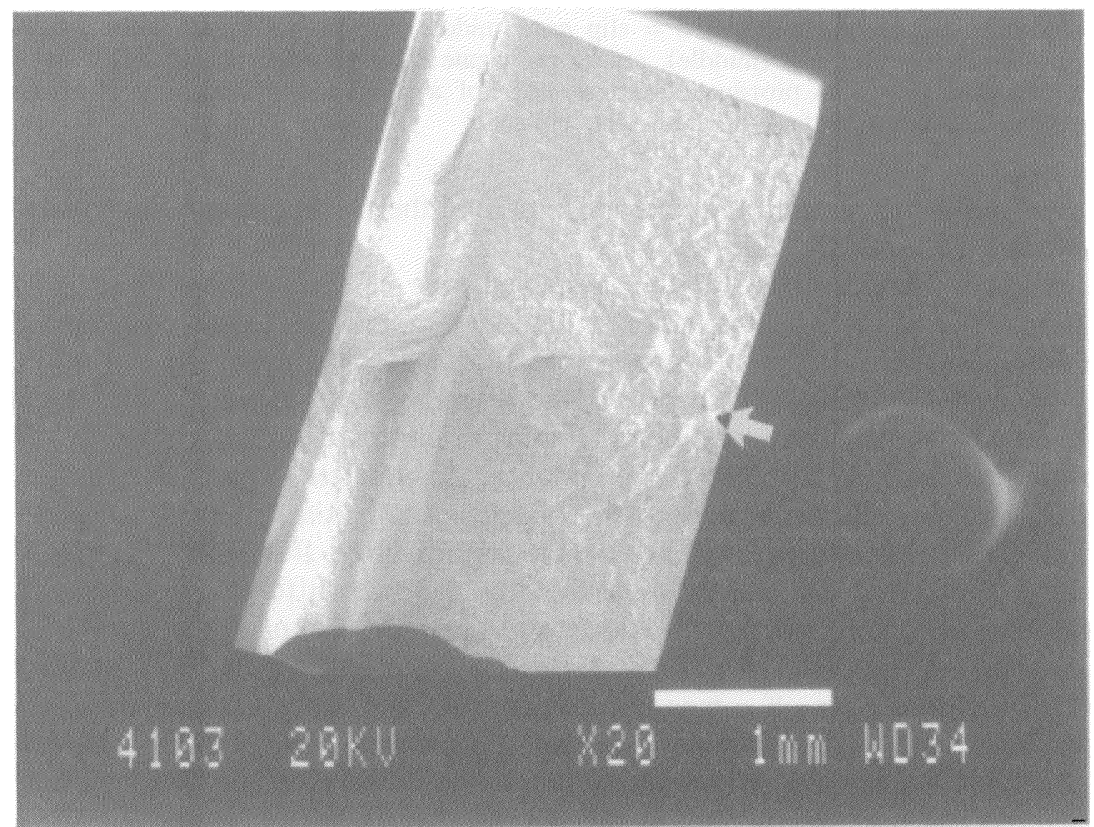

(b) 


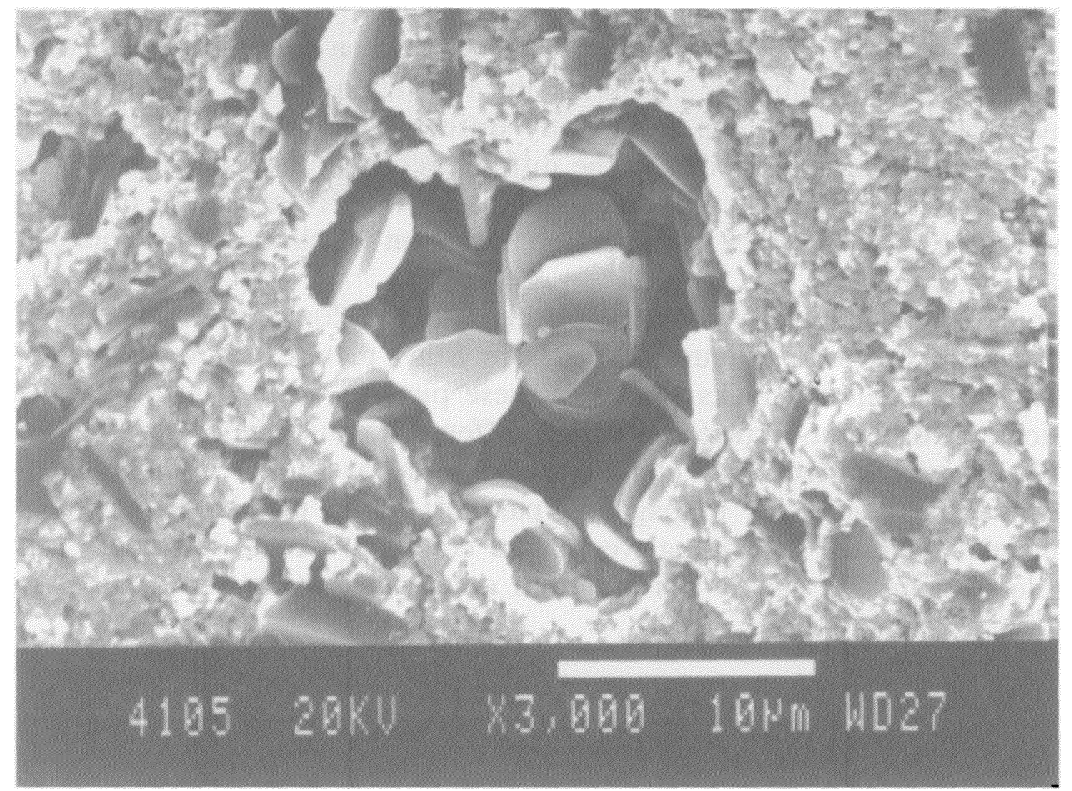

(c)

Figure 5 Fracture surface SEM of injection moulded samples. Arrows indicate the fracture origin. (a) tensile surface not polished; (b) tensile surface polished, low magnification; (c) closer view of the fracture origin in (b).

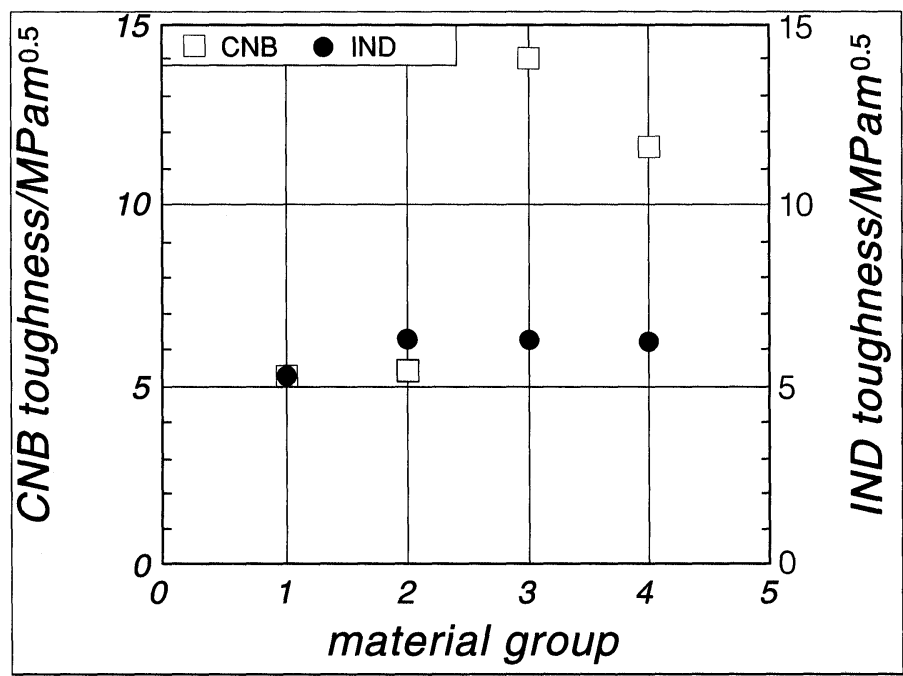

Figure 6 Fracture toughness $\left(\mathrm{K}_{\mathrm{IC}}\right)$ values for different material groups. CNB, and IND represents chevron notched beam, and indentation, respectively. 1 = slip cast matrix (TZ3YS); $2=$ injection moulded composite; 3 = slip cast composite, crack propagate from an edge of a platelet for CNB, indentations were made on the cut surface for IND; $4=$ slip cast composite, cracks propagate from a surface of a platelet for $\mathrm{CNB}$, indentations were made on the large surface normal to the cut for IND. 
For composite samples with strong textures prepared by slip casting (group 3 and 4), $\mathrm{K}_{\mathrm{IC}}$ values measured by both methods are higher than those for the matrix material formed by the same technique, indicating the toughening effect of the platelets. The $\mathrm{K}_{\mathrm{IC}}$ values from CNB and IND are greatly different for samples in group 3 and 4., which is thought to be mainly due to the different characteristics of the two measuring techniques, and the different properties on the surface from inside the body. Note, however, the effect of crack propagation direction relative to the platelet is not significant.

As for the toughening effect of the platelets in the composite, several toughening mechanisms are operating. Figure 7 (a-d) are SEM pictures showing the interaction of a crack and platelets. Cracks shown in these pictures were introduced by diamond indentations on different surfaces on which different textures were observed. Breakage of the platelets by a crack was commonly observed as shown in Figure 7 (a, c, d), except when the crack was propagating parallel to the platelet (Figure 7b), where matrix-platelet interface debonding were more common. Crack deflection, arresting at the platelet (Figure 7a) and re-starting from other places (Figure 7a, b, c) were also observed.

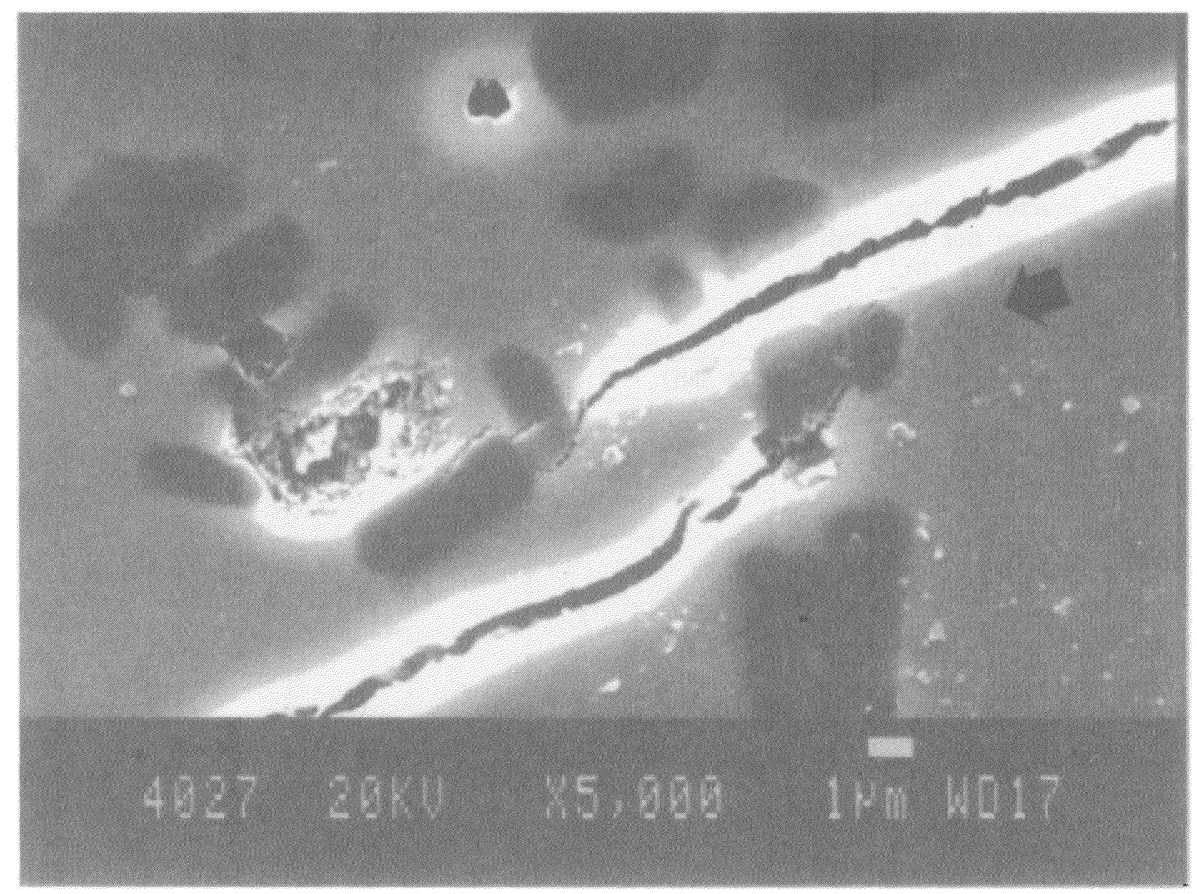

(a) 
TEXTURE FORMED BY PLATELET ALIGNMENT

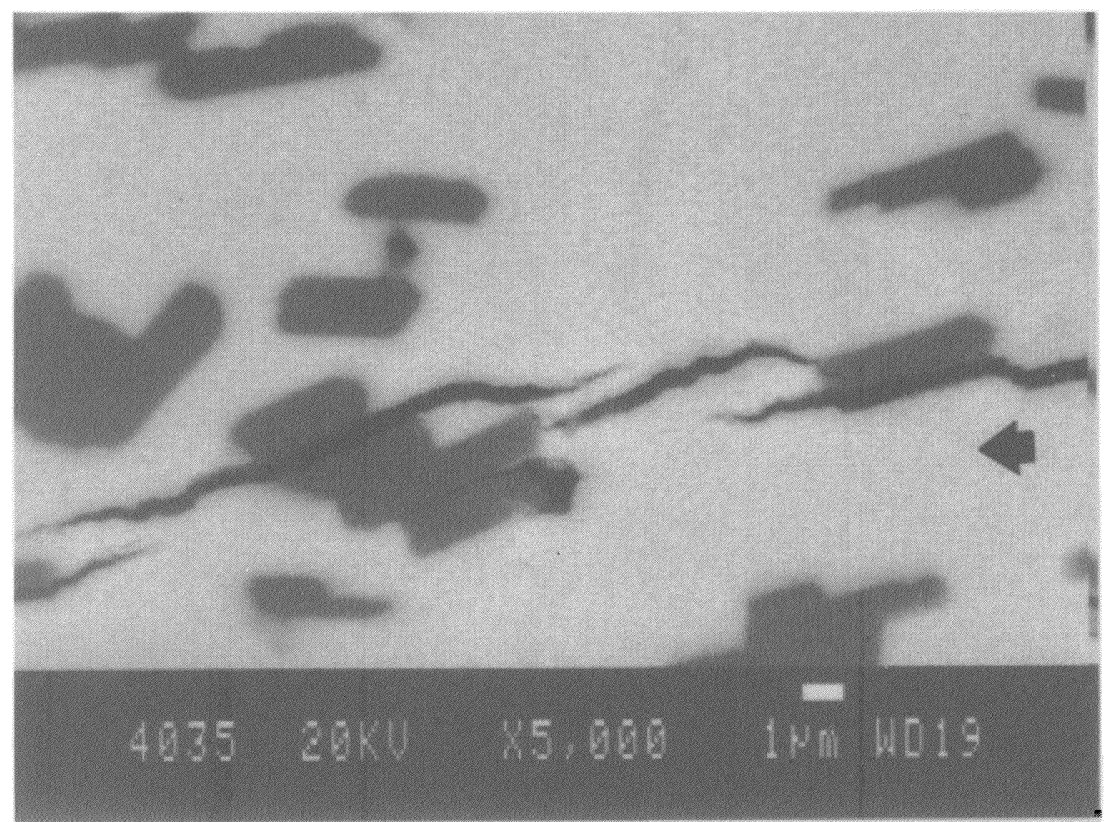

(b)

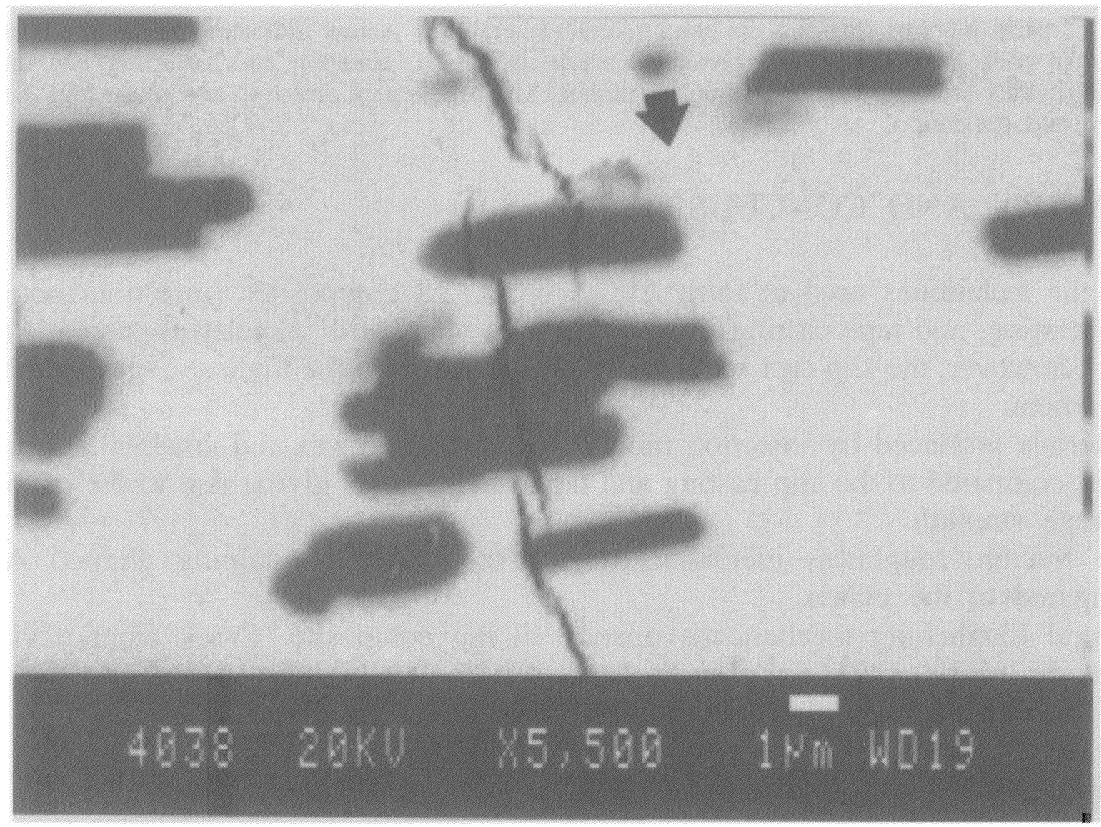

(c) 


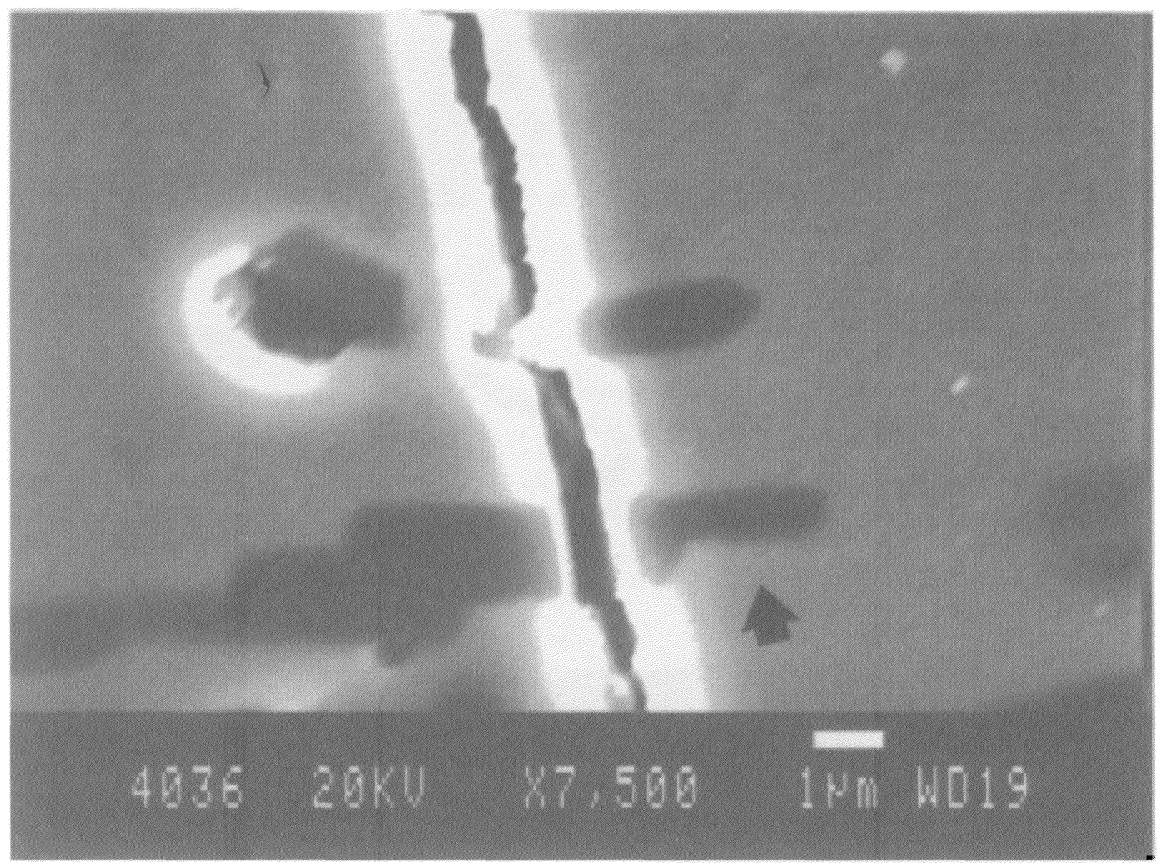

(d)

Figure 7 SEM pictures showing the crack-platelet interaction. Arrow indicates the crack propagation direction in each case, (a) platelet breakage, crack deflection, arresting and restarting; (b) interface debonding, crack arresting and restarting; (c) platelet breakage, crack arresting and restarting; (d) crack breakage and deflection.

\section{SUMMARY AND CONCLUSIONS}

- All the techniques used to form $\mathrm{Al}_{2} \mathrm{O}_{3 \mathrm{pl}}$ - TZ3YS composites (injection moulding, slip casting, and tape casting) resulted in some degree of platelet alignment. In this work however, the slip cast specimens appeared to have the highest degree of platelet alignment.

- Materials produced by injection moulding exhibited fewer and smaller internal defects, compared to the slip casting and tape casting, thus giving rise to the maximum average strength.

- The fracture toughness increased for the composites containing aligned $\mathrm{Al}_{2} \mathrm{O}_{3 \mathrm{pl}}$ compared to the matrix.

- Several toughening mechanisms operate in the composite. Crack front deviation, crack deflection, crack arresting at the platelets, platelet matrix interface debonding, and breakage of the platelets were observed.

\section{Acknowledgement}

Technical support provided by P.V. Jensen, P. Skov-Hansen, and T.R. Stauss are greatly acknowledged. The authors would like to thank, U.P.V. Skands IMSOR/IMM. Technical University of Denmark, L.H. Christensen and P. Wahlberg, Dept. of Chemistry, Danish Technological Institute (DTI) for the quantitative platelet orientation analysis using 
image processing, and providing Figure 2. We would also like to thank N.P. Dalskov, Dept. of plastic technology, DTI; and N.Kr. Nielsen, Haldor Topsøe A/S, Denmark, for providing injection moulded samples, the composite tapes and the relevant information.

\section{References}

1. Akimune, Y., Katano, Y. and Shichi, Y. (1988). Mechanical properties and microstructure of an air-annealed SiC-whisker/Y-TZP composite. Adv. Ceram. Mater., 3, 138-142.

2. Claussen, N., Weisskopf, K. L. and Ruhle, M. (1986). Tetragonal zirconia polycrystals reinforced with SiC-whiskers. J. Am. Ceram. Soc., 69, 288-292.

3. Heussner, K. H. and Claussen, N. (1989). Yttria- and ceria- stabilized tetragonal zirconia polycrystals (Y-TZP, Ce-YZP) reinforced with $\mathrm{Al}_{2} \mathrm{O}_{3}$ platelets. J. Eur. Ceram. Soc., 5, 193-200.

4. Huang, X-N. and Nicholson, P. S. (1993). Mechanical properties and fracture toughness of $\alpha$-Al $\mathrm{O}_{3}$ - platelet - reinforced Y-PSZ composites at room and high temperatures. J. Am. Ceram. Soc., 76, 1294-1301.

5. Jin, S., Tiefel, T. H., Sherwood, R. C., Davis, M. E., van Dover, R. B., Kammlott, G. W., Fastnatch, R. A. and Keith, H. D. (1989). High critical currents in Y-Ba-Cu-O superconductors. Appl. Phys. Lett., 52, 2074-2079.

6. Kahn, J. S. and Bragg, R. H. (1968). Quantitative determination and analysis of texture. In Ceramic Microstructures, edited by Fulrath, R. M. and Pask, J. A., pp. 207-230. New York: John Wiley.

7. Kihara, M., Ogata, T., Nakamura, K. and Kobayashi, K. (1988). Effect of $\mathrm{Al}_{2} \mathrm{O}_{3}$ addition on mechanical properties and microstructures of Y-TZP. J. Jpn. Ceram. Soc., 96, 646-653.

8. Kumakura, H., Togano, K., Maeda, H., Kase, J. and Morimoto, T. (1991). Anisotropy of critical current density in textured $\mathrm{Bi}_{2} \mathrm{Sr}_{2} \mathrm{Cu}_{2} \mathrm{O}_{x}$ tapes. Appl. Phys. Lett., 58, 2830-2834.

9. Roberts, J. M., Singh, J. P. and Scattergood, R. O. (1991). Microstructure and properties of aluminawhisker- reinforced tetragonal zirconia polycrystal matrix composites. Ceram. Eng. Sci. Proc., 12, 1193-1200.

10. Sandlin, M. S. and Bowmen, K. J. (1992). Green body processing effects on SiC whisker textures in alumina matrix composites. Ceram. Eng. and Sci. Proc., 13, 661-668.

11. Sato, T., Fujshiro, H., Endo, T. and Shimada, M. (1987). Thermal stability and mechanical properties of yttria-doped tetragonal zirconia polycrystals with dispersed alumina and silicon carbide particle. J. Mat. Sci., 22, 882-886.

12. Sato, T., Fujshiro, H., Endo, T. and Shimada, M. (1988). Thermal stability and mechanical properties of yttria-doped tetragonal zirconia/alumina composite. In Science of Ceramics, 14, edited by Taylor, D., pp. 843-848. The Institute of ceramics.

13. Tsukuma, K., Ueda, K. and Shimada, M. (1985a). Strength and fracture toughness of isostatically hot-pressed composites of $\mathrm{Al}_{2} \mathrm{O}_{3}$ and $\mathrm{Y}_{2} \mathrm{O}_{3}$-partially-stabilized $\mathrm{ZrO}_{2}$. J. Am. Ceram. Soc., 68, C4-C5.

14. Tsukuma, K., Ueda, K., Matsushita, K. and Shimada, M. (1985b). High temperature strength and fracture toughness of $\mathrm{Y}_{2} \mathrm{O}_{3}$-partially-stabilized $\mathrm{ZrO}_{2} / \mathrm{Al}_{2} \mathrm{O}_{3}$ composites. J. Am. Ceram. Soc., 68, C56-C58.

15. Warner, D. A. and Sørensen, O. T. (1991). Ceramic platelet composites produced by pressure filtration. In Euro - Ceramics II, 2, edited by Ziegler, G. and Hausner, H., pp. 1547-1551. Deutsche Keramische Gesellschaft e.v.

16. Warner, D. A., Warner, K. A., Jull Jensen, D. and Sørensen, O. T. (1992). Orientation of platelet reinforcements in ceramic matrix composites produced by pressure filtration. Ceramic Engineering and Science Proceedings, 13, 172-179.

17. Watanabe, H., Kimura, T. and Yamaguchi, T. (1989). Particle orientation during tape casting in the fabrication of grain-oriented bismuth titanate. J. Am. Ceram. Soc., 72, 289-293.

18. Watanabe, H., Kimura, T. and Yamaguchi, T. (1991). Sintering of platelike bismuth titanate powder compacts with preferred orientation. J. Am. Ceram. Soc., 74, 139-147.

19. Wu, M-X., Messing, G. L. and Amateau, M. F. (1991). Laminate processing and properties of oriented SiC whisker-reinforced composites. Ceram. Trans., 19, 665-675. 